\title{
SURGICAL TREATMENT OF MULTIPLE ANEURYSMS IN A PATIENT WITH EHLERS-DANLOS SYNDROME
}

Norihiko Oka, MD, Shigeyuki Aomi, MD, Hideyuki Tomioka, MD, Masahiro Endo, MD, and Hitoshi Koyanagi, MD, Tokyo, Japan

Ehlers-Danlos syndrome is a rare inherited disorder of the connective tissue that has been divided into 10 types according to the clinical course and inheritance. In type IV EhlersDanlos syndrome extreme fragility of the arteries is associated with multiple aneurysm formation, spontaneous rupture, and dissection. ${ }^{1}$ We report on a patient with Ehlers-Danlos syndrome who had multiple aneurysms and acute enlargement of the sinus of Valsalva. Four operations were successfully performed. Abdominal aortic aneurysm, extended aneurysm of the thoracic aorta involving the aortic arch, aneurysm of the aortic root, and aneurysm of the superior mesenteric artery were repaired. To our knowledge, this is the first report of 4 successful graft replacements in a patient with Ehlers-Danlos syndrome.

Clinical summary. A 46-year-old man was admitted to our department for treatment of enlargement of the sinus of Valsalva. His father had died of amyotrophic lateral sclerosis at 68 years of age, and his mother died of a rupture of a dissecting abdominal aorta at 62 years of age. His height was $180 \mathrm{~cm}$ and weight was $77 \mathrm{~kg}$. There were no characteristic findings in the skin and joints, but a keloid scar on his abdomen resulted from a delay in healing. He had received graft replacement for an aneurysm of the abdominal aorta 5 years previously and extended replacement of the thoracic aorta involving the aortic arch 1 year later. The Ehlers-Danlos syndrome was diagnosed histopathologically by staining of the resected aortic wall after the second operation, which showed deficiency of type III collagen.

One year after graft replacement of the aortic arch, an aortogram showed second-degree aortic regurgitation and acute enlargement of the sinus of Valsalva. Computed tomography revealed the increase in size of the sinus of Valsalva (from 3.8$6.6 \mathrm{~cm}$ in 4 years). Also, the superior mesenteric artery showed aneurysmal dilatation $(1.8 \mathrm{~cm}$ in diameter). The approach was made through a median sternotomy, and the aneurysm was exposed. He was placed on cardiopulmonary bypass after aortic cannulation to the previous graft and bicaval drainage. The heart was arrested with cold blood cardioplegic solution, and the ascending aorta was opened. The sinus of Valsalva showed annuloaortic ectasia and dissection just above the orifice of the right coronary artery. Composite valve graft replacement was performed by using a $28-\mathrm{mm}$

From the Department of Cardiovascular Surgery, The Heart Institute of Japan, Tokyo Women's Medical University, Tokyo, Japan.

J Thorac Cardiovasc Surg 2001;121:1210-1

Copyright () 2001 by The American Association for Thoracic Surgery

0022-5223/2001 $\$ 35.00+0 \quad \mathbf{1 2 / 5 4 / 1 1 1 6 4 4}$

doi:10.1067/mtc.2001.111644 conduit with a 25-mm St Jude Medical bileaflet prosthetic valve (St Jude Medical, Inc, St Paul, Minn). The coronary arteries were anastomosed to the site hole of the composite graft by the button technique. The composite graft was anastomosed end to end to the previous graft and was wrapped in the wall of the aneurysm. The postoperative period was uneventful, and he underwent successful graft replacement of the superior mesenteric arterial aneurysm 5 months after the composite valve graft replacement.

Discussion. Ehlers-Danlos syndrome is a rare inherited disorder of the connective tissue. It has been divided into 10 types according to the clinical course and inheritance. ${ }^{1}$ In type IV Ehlers-Danlos syndrome (about $4 \%$ of the cases) extreme fragility of the arteries is associated with multiple aneurysm formation, spontaneous rupture, and dissection. In 1975, Pope and associates $^{2}$ detected type III collagen, which is responsible for the integrity of blood vessel walls in variable quantities in patients with type IV Ehlers-Danlos syndrome. They subdivided type IV Ehlers-Danlos syndrome into 3 further types: (1) classic type (type III collagen defect complete); (2) long-lived type (type III collagen defect incomplete); and (3) atypical type. Our case was diagnosed as being of the long-lived type.

Subsequently, many mutations in the COL $3 A 1$ gene have been found to account for the deficiency of type III procollagen. ${ }^{3}$ Patients with type IV Ehlers-Danlos syndrome die young, and most deaths result from arterial rupture. ${ }^{4}$

Raman and colleagues ${ }^{5}$ described 2 composite valve graft replacements for patients with Ehlers-Danlos syndrome. Babatasi and associates ${ }^{6}$ reported staged replacement of the total aorta in a case of aortic dissection of Ehlers-Danlos syndrome.

To our knowledge, completed consecutive safe operations in a case of multiple aneurysm of Ehlers-Danlos syndrome have not been reported until now. We performed each operation by using the usual techniques. There were no major complications, and the postoperative course is good.

In summary, we treated a patient with Ehlers-Danlos syndrome with multiple aneurysms. Four graft replacements were completed successfully. Ehlers-Danlos syndrome type IV often has multiple aneurysms with a tendency for rapid enlargement as seen in Marfan syndrome. It is suggested that either consecutive or extensive operations should be performed.

Received for publication Aug 2, 2000; accepted for publication Sept 1, 2000.

Address for reprints: Norihiko Oka, MD, Department of Cardiovascular Surgery, The Heart Institute of Japan, Tokyo Women's Medical University, 8-1 Kawada-cho, Shinjuku-ku, Tokyo 162-8666, Japan (E-mail: norihiko@rr.iij4u.or.jp). 


\section{REFERENCES}

1. Barabas AP. Vascular complications in Ehlers-Danlos syndrome. J Cardiovasc Surg 1972;13:160-7.

2. Pope FM, Martin GR, Lichtenstein JR, et al. Patients with EhlersDanlos syndrome type IV lack type III collagen. Proc Natl Acad Sci 1975;72:1314-6.

3. Reed EP. Ehlers-Danlos syndrome. N Engl J Med 2000;342:730-2.

4. Melanie P, Ulrike S, Andrea SF, et al. Clinical and genetic fea- tures of Ehlers-Danlos syndrome type IV, the vascular type. N Engl J Med 2000;342:673-80.

5. Raman J, Saldanha RF, Esmore DS, et al. The Bentall procedure: a surgical option in Ehlers-Danlos syndrome. J Cardiovasc Surg (Torino) 1988;29:647-9.

6. Babatasi G, Massetti M, Bhoyroo S, Khayat A. Pregnancy with aortic dissection in Ehler-Danlos syndrome: staged replacement of the total aorta (10-year follow-up). Eur J Cardiothorac Surg 1997;12:671-4 